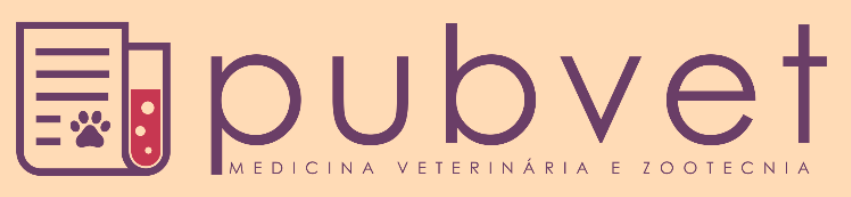

https://doi.org/10.31533/pubvet.v16n02a1034.1-5

\title{
Quimioterapia e criocirurgia no tratamento de carcinoma de células escamosas em gata: Relato de caso
}

\author{
Ciro José Sousa de Carvalho $₫ *$ * \\ *Prof. Dr. Centro Universitário - Instituto Tocantinense de Pós-Graduação, Palmas-TO. E-mail: medicinaveterinaria@faculdadeitop.edu.br
}

Resumo. O carcinoma de células escamosas é um neoplasma maligno que acomete a epiderme, em felinos a incidência é maior em animais de pele clara ou despigmentada, afetando as orelhas, plano nasal, pálpebras e olhos. É um tumor agressivo localmente e com baixa taxa de metástase. O diagnóstico baseia-se em exames clínicos e laboratoriais. O presente relato tem como objetivo descrever um caso de carcinoma de células escamosas em uma felina, atendido em uma clínica veterinária particular na cidade de Palmas, Tocantins, destacando a utilização da quimioterapia associada à criocirurgia como tratamento promissor desta patologia.

Palavras-chave: Criocirurgia, carboplatina, carcinoma, felino

\section{Chemotherapy associated with cryosurgery in the treatment of squamous cell carcinoma in a female: Case report}

\begin{abstract}
Squamous cell carcinoma is a malignant neoplasm that affects the epidermis, in cats the incidence is higher in animals with fair or depigmented skin, affecting the ears, flat nasal, eyelids and eyes. It is a locally aggressive tumor with a low metastasis rate. Diagnosis is based on clinical and laboratory tests. This report aims to describe a case of squamous cell carcinoma in a feline, treated at a private veterinary clinic in the city of Palmas, Tocantins, highlighting the use of chemotherapy associated with cryosurgery as a promising treatment for this pathology.
\end{abstract}

Keywords: Cryosurgery, carboplatin, carcinoma, feline

\section{Quimioterapia asociada a la criocirugía en el tratamiento del carcinoma de células escamosas en una gata: reporte de un caso}

\begin{abstract}
Resumen. El carcinoma de células escamosas es una neoplasia maligna que afecta a la epidermis, en gatos la incidencia es mayor en animales de piel clara o despigmentada, afectando las orejas, plano nasal, párpados y ojos. Es un tumor localmente agresivo con una baja tasa de metástasis. El diagnóstico se basa en pruebas clínicas y de laboratorio. Este informe tiene como objetivo describir un caso de carcinoma de células escamosas en un felino, tratado en una clínica veterinaria privada de la ciudad de Palmas, Tocantins, destacando el uso de quimioterapia asociada a la criocirugía como un tratamiento prometedor para esta patología.
\end{abstract}

Palabras clave: Criocirugía, carboplatino, carcinoma, felino

\section{Introdução}

Dentre as neoplasias existentes, as de origem cutânea estão entre as neoplasias mais comuns em animais domésticos (Fernandes et al., 2015). O carcinoma das células escamosas (CCEs) é um neoplasma maligno que acomete a epiderme em felinos (Barros et al., 2008; Chacur et al., 2014). A 
incidência é maior em animais de pelagem branca, com pouco pêlo e pigmento, pode afetar orelhas, plano nasal, pálpebras e olhos. O tumor é bastante agressivo localmente e possui baixa taxa de metástase para linfonodos e pulmões.

O diagnóstico é feito com base em sinais clínicos e exames laboratoriais, tais como, citologia aspirativa e biopsia da massa tumoral (Corrêa et al., 2018; Costa et al., 2013). A queixa mais relatada pelos proprietários é a presença de massa, espessamento ou ulceração da pele. (Ettinger et al., 2017). Segundo Ferreira et al. (2006). A afecção pode estar presente em animais por um longo período, como feridas que não cicatrizam e as lesões podem ser hiperemicas, proliferativas, crostosas, evoluindo posteriormente para formas ulcerativas que invadem tecidos adjacentes. O diagnóstico diferencial para o CCE tegumentar inclui distúrbios pré-neoplásicos, neoplásicos ou não neoplásicos, com apresentação granulomatosa ou erodoulcerativa, podendo-se citar dermatite/queratose atínica, carcinoma de células basais, acantoma queratinizante infundibular, carcinomas anaplásicos, melanoma amelânico, mastocitoma, fibrossarcoma, hemangiossarcoma, tumores dos folículos pilosos, tumores das glândulas sebáceas, corpo estranho, leishmaniose, esporotricose, criptococose, abscesso, actinomicose, nocardiose, complexo pênfigo, complexo granuloma eosinofílico, paniculite, farmacodermia, dermatopatias alérgicas, ação tecidual de ácaros, dentre outros (Bastos et al., 2017; Camargo et al., 2008; Carneiro et al., 2012; Paranhos, 2014). Diante das opções de tratamento, a carbopatina é um derivado platinado de segunda geração, que atua ligando-se ao DNA de forma a impedir a síntese protéica, sendo considerada um fármaco ciclo celular inespecífico (Carneiro et al., 2012), a criocirurgia é uma técnica que promove o congelamento e descongelamento tecidual resultando em crionecrose, e seu sucesso depende da quantidade e ciclos, velocidade, tempo, tipo celular acometido e temperatura (Costa et al., 2013). A carboplatina é um derivado platinado de segunda geração, que atua ligando-se ao DNA de forma a impedir a síntese proteica, sendo considerado um fármaco ciclo celular inespecífico (Carneiro et al., 2012). O presente relato tem como objetivo descrever um caso de carcinoma de células escamosas em uma felina, atendido em uma clínica veterinária particular na cidade de Palmas, Tocantins, destacando a utilização da quimioterapia associada à criocirurgia como tratamento promissor desta patologia.

\section{Material e métodos}

Foi atendida em uma clínica particular na cidade de Palmas-Tocantins, uma fêmea felina com sete anos de idade, ovariohisterectomizada, sem raça definida, vacina quíntupla em dia, negativa para o teste que detecta doenças virais como imunodeficiência felina e leucemia viral felina (Fiv/Felv).

Durante anamnese, tutora relatara origem de lesão na orelha de sua gata não responsiva a tratamentos anteriores por 6 meses. Ao exame clínico minucioso foi constatado lesões ulcerativas com crostas em pina auricular, borda da orelha direita e face interna da orelha, paciente normocorada, normorexia, normúria, normoquesia, temperatura retal em $37,8{ }^{\circ} \mathrm{C}$ e ausculta de campo cardiopulmonar sem alterações evidentes.

Foram realizados exames de hemograma, perfil bioquímico (ureia, creatinina, alanina aminotransferase, aspartato aminotransferase, fosfatase alcalina, proteínas totais, albumina, globulina). No momento da consulta solicitado exames de imagens complementares para correto estadiamento do paciente oncológico, inicialmente solicitado a radiografia torácica em três projeções (ventrodorsal, lateral direita e lateral esquerda). Optou-se pela realização de raspado das lesões da orelha para avaliação citopatológica, onde foram observados: pleomorfismo moderado, anisocitose, anisocariose, cromatina frouxa, evidenciação de nucléolos e basofilia citoplasmática compatíveis com CCE.

O tratamento inicial realizado foram 4 sessões de quimioterapia a cada 21 dias por via IV de Carboplatina na dose de $200 \mathrm{mg} / \mathrm{m}^{2}$ associada a prednisolona $2 \mathrm{mg} / \mathrm{kg} /$ dia como coadjuvante na terapia antineoplásica. Notou-se regressão inicial das lesões após a segunda aplicação. Entre a segunda e terceira aplicação de quimioterapia, a paciente apresentou quadro de leucopenia leve, onde optou-se por administrar filgastrine $0,25 \mathrm{ml}$ por via subcutânea três vezes por semana, o que levou aos índices normais no leucograma da paciente. Ao final dos ciclos de carboplatina, notou-se regressão de aproximadamente 95\% do tamanho das lesões iniciais. Diante da redução notória, optou-se por prosseguir com procedimento de criocirurgia na tentativa de erradicar o neoplasma. Foi realizado então procedimento de criocirurgia com criocautério a base de gases fluoretados. Levou-se em conta a distância de 1-2 cm 
da lesão para realização do procedimento com três aplicações de oito segundos intercaladas por intervalos de 1 minuto. A medicação pré-anestésica utilizada foi morfina e acepromazina. No pósoperatório, o animal recebeu maxicam $0,2 \%$ via subcutânea, Tramadol $0,3 \mathrm{ml}$ via intramuscular, agemoxi $0,5 \mathrm{ml}$ via intramuscular, algivet $0,2 \mathrm{ml}$ diluído durante 5 dias. Apenas uma sessão foi instituída de criocirurgia, 21 dias após o procedimento a paciente foi reavaliada e observou-se ausência de lesões e tecido de cicatrização de aspecto normal. Paciente foi acompanhada a cada três meses até completar 12 meses após o procedimento e não houve recidiva.

\section{Resultados e discussão}

A paciente descrita neste relato apresenta pelagem clara, sendo mais susceptível ao carcinoma de células escamosas conforme descrito por (Daleck et al., 2016; Ettinger et al., 2017). Em gatos de pele clara ou despigmentados, o índice de desenvolvimento de neoplasias de pele é alto, podendo ocorrer tumores benignos e malignos (Dias et al., 2015; Ettinger et al., 2017). A paciente atendida tinha segundo sua tutora, o hábito de expor-se ao sol diariamente, o que neste relato é sugestivo o aparecimento deste neoplasma por radiação UV absorvida, que ocasiona lesão tissular, podendo lesionar também DNA das células escamosas devido a formação de radicais livres, podendo ocorrer mutações e posteriormente a neoplasia em si (Coelho et al., 2016; González \& Silva, 2008).

No relato descrito a lesão perdurava há 6 meses, o que é relatado por Noleto (2009) que descreve a lesão inicial de CCE pode estar presente por meses ou anos, onde a história clínica está associada a um ferimento que não cicatriza. Nos CCE associados à luz solar, os sinais podem progredir vagarosamente ou crescer e diminuir por meses (Barros et al., 2008; Ramos et al., 2007; Rosolem et al., 2012) (Figura 1).

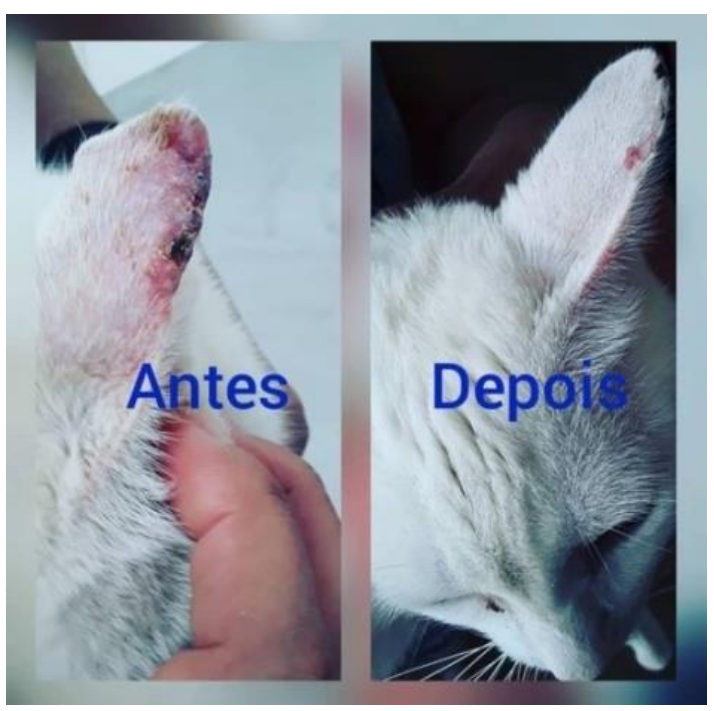

Figura 1. Lesão em pina auricular antes do tratamento e depois do tratamento com 4 ciclos de carboplatina, a cada 21 dias, dose $200 \mathrm{mg} / \mathrm{m}^{2} \mathrm{IV}$.

O uso da citologia é vantajoso para confirmação da doença, por ser uma técnica rápida, fácil e pouco invasiva (Rosolem et al., 2012). Em gatos acometidos pelo carcinoma de células escamosas, notam-se lesões proliferativas, crostosas ou ulcerativas, que podem sangrar facilmente, atingindo mais frequentemente a pele, com pêlos brancos do pavilhão auricular, nariz ou pálpebras ( $\underline{\text { Hnilica \& Medleau, }}$ 2012).

O quimioterápico utilizado está em acordo com a literatura que descreve a carboplatina como um composto platinado com ação idêntica à cisplatina, mas que pode ser utilizado em gatos. Disponível em formulações injetáveis. A administração a animais com infecções, insuficiência hepática, renal e auditiva deve ser cautelosa, para além disso está contraindicada em doentes com mielossupressão. Indicações de utilização iguais à cisplatina (Carneiro et al., 2012; Plumb, 2018).

O grande objetivo da quimioterapia é a total erradicação das células tumorais ou cura, o que nem sempre é possível. Assim, em Medicina Veterinária, promove-se frequentemente a remissão tumoral e 
cuidados paliativos, garantindo uma melhoria ou manutenção da qualidade de vida do animal, e aumentando (se possível) a sua esperança média de vida (Nelson \& Couto, 2015). O que se verifica é que uma única sessão de quimioterapia não é suficiente para eliminar todas as células tumorais, pelo que os tratamentos são administrados de forma pulsátil, num curto espaço de tempo, para evitar/diminuir a repopulação das células neoplásicas. Na prática, a frequência das sessões de quimioterapia é limitada pela toxicidade dos fármacos nos tecidos normais e respetiva capacidade de recuperação. No caso da mielossupressão, induzida por fármacos como a ciclofosfamida ou a doxorrubicina, verifica-se uma diminuição da linha celular branca atingindo-se aos 5-10 dias pós-sessão o nadir, ou seja, o valor celular mais baixo, com recuperação aos 21 dias pós-sessão. Esta ocorrência limita a frequência de administrações a ciclos de 3 semanas (Dobson \& Lascelles, 2011).

A criocirurgia é um método de escolha devido a sua capacidade de possuir um dos principais mecanismos de ação a destruição tecidual devido à hipotermia, ocasionando morte celular por isquemia. Indica-se o procedimento para mais de 60 tipos de lesões dermatológicas (Jericó et al., 2015). O principal objetivo da crioterapia é a destruição de células-alvo acarretando o mínimo de lesão do tecido normal. O processo de congelamento e descongelamento em crioterapia é chamado de ciclo, o qual há produção de cristais no processo de congelamento havendo equilíbrio osmótico na célula, o que levará a maior concentração de eletrólitos dentro das células, à medida que a concentração desses eletrólitos aumenta, maior é a morte celular (Jericó et al., 2015) (Figura 2).

O caso relatado anteriormente, foi baseado em exame citológico e clínico, diante dos resultados optou-se por instituir um tratamento onde associou-se quimioterapia antineoplasica injetável associada a criocirurgia, que respondeu bem a estas terapias, onde a paciente ficou livre da doença em acompanhamento clínico oncológico por 12 meses e está livre até os dias atuais (Figura 3).

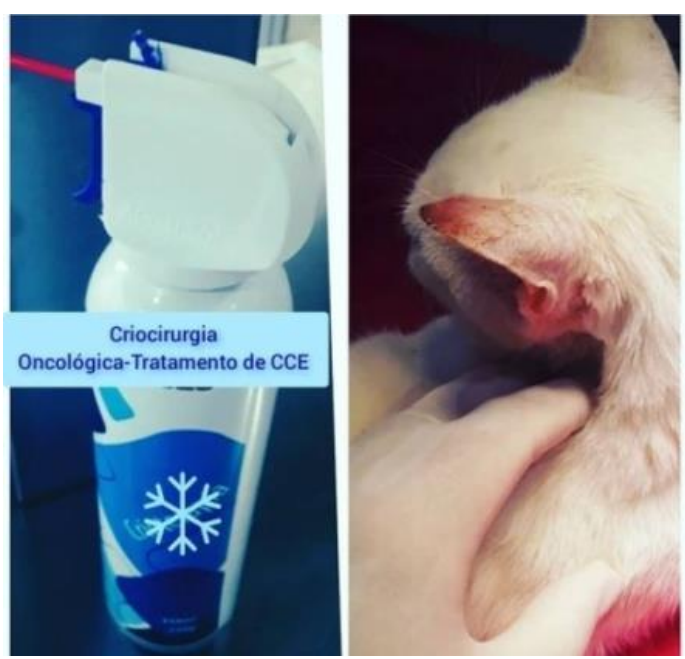

Figura 2. Paciente após sessão de criocirurgia.

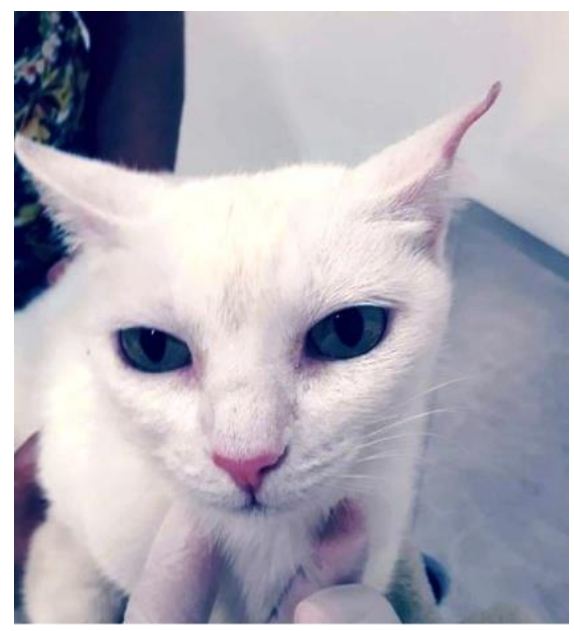

Figura 3. Paciente livre de doença clínica 12 meses após quimioterapia associada a criocirurgia.

\section{Conclusão}

O carcinoma de células escamosas acomete principalmente felinos de pele branca ou despigmentada, trata-se de uma neoplasia maligna com alto poder invasivo localmente. Medidas preventivas com relação à exposição solar e o uso de protetores solares podem inibir o aparecimento destas neoplasias. $\mathrm{O}$ diagnóstico precoce realizado por oncologista veterinário de qualquer neoplasia é crucial para um bom prognóstico, onde pode-se combinar terapias para tratar o câncer. No relato descrito constatou-se a eficácia da quimioterapia associada à criocirurgia.

\section{Referências bibliográficas}

Barros, R. M., Jacobina, G. J., Ecco, R., Silva, C. E. V., \& Galera, P. D. (2008). Carcinoma das células escamosas multicêntrico em cão. Revista Brasileira de Saúde e Produção Animal, 9(1), 103-108.

Bastos, R. S. C., Farias, K. M., Lopes, C. E. B., Pacheco, A. C. L., \& Araújo Viana, D. (2017). Estudo retrospectivo de neoplasias cutâneas em cães da região metropolitana de Fortaleza. Revista Brasileira de Higiene e Sanidade Animal, 11(1), 39-53. 
Camargo, L. P., Conceição, L. G., \& Santos Costa, P. R. (2008). Neoplasias melanocíticas cutâneas em cães: estudo retrospectivo de 68 casos (1996-2004). Brazilian Journal of Veterinary Research and Animal Science, 45(2), 138-152.

Carneiro, R. A., Pimenta, C. N., Horta, R. S., Lavalle, G. E., \& Paes, P. R. O. (2012). Quimioterapia intralesional com carboplatina no tratamento do carcinoma espinocelular em uma gata relato de caso. Revista Clínica Veterinária, 17(98), 70-94.

Chacur, M. G. M., Fachini, B. A., Yamasaki, L., Basso, K., Sanches, O. C., \& Pessoa, V. M. (2014). Carcinoma das células escamosas no prepúcio com invasão vertebral em equino. Semina: Ciências Agrárias, 35(3), 1383-1388.

Coelho, H. E., Santos, R. L., \& Alessi, A. C. (2016). Patologia veterinária. Coelho.

Corrêa, J. M. X., Oliveira, N. G. S. G., Silva, F. L., Michel, A. F. R. M., Lavoer, M. S. L., Silva, E. B., \& Carlos, R. S. A. (2018). O Diagnóstico preciso muda o prognóstico do paciente felino com carcinoma de células escamosas? Revista Científica de Medicina Veterinária - Pequenos Animais e Animais de Estimação, 15(46), 54-60.

Costa, J., Paiva, V., Ramos, S., Huppes, R., Bardoza, A., Raiser, A. G., Calderón, L. G. R., \& Ramírez, R. (2013). Criocirurgia no tratamento de carcinoma de células escamosas em cão. Revista Colombiana de Ciência Animal, 5(1), 213-221.

Daleck, C. R., Fonseca, C. S., \& Canola, J. C. (2016). Oncologia em cães e gatos. Roca.

Dias, F., Dias, L., Pereira, L., Cabrini, T., \& Rocha, J. (2015). Neoplasias orais nos animais de companhia-Revisão de literatura. Revista Científica Eletrônica de Medicina Veterinária, 20(1), 1-9.

Dobson, J. M., \& Lascelles, B. D. X. (2011). BSAVA manual of canine and feline oncology (Issue Ed. 3). British Small Animal Veterinary Association.

Ettinger, S. J., Feldman, E. C., \& Cote, E. (2017). Textbook of Veterinary Internal Medicine-eBook. Elsevier Health Sciences.

Fernandes, C. C., Medeiros, A. A., Magalhães, G. M., Szabó, M. P. J., Queiroz, R. P., Silva, M. V. A., \& Soares, N. P. (2015). Frequência de neoplasias cutâneas em cães atendidos no hospital veterinário da Universidade Federal de Uberlândia durante os anos 2000 a 2010. Bioscience Journal, 31(2), 541-548.

Ferreira, I., Rahal, S. C., Ferreira, J., \& Corrêa, T. P. (2006). Terapêutica no carcinoma de células escamosas cutâneo em gatos. Ciência Rural, 36(3), 1027-1033.

González, F. H. D., \& Silva, S. C. (2008). Patologia clínica veterinária: texto introdutório. Universidade Federal do Rio Grande do Sul.

Hnilica, K. A., \& Medleau, L. (2012). Dermatologia de pequenos animais: atlas colorido e guia terapêutico. Roca.

Jericó, M. M., Kogika, M. M., \& Andrade Neto, J. P. (2015). Tratado de medicina interna de cães e gatos. Guanabara Koogan.

Nelson, R. W., \& Couto, C. G. (2015). Medicina interna de pequenos animais (Issue 1). Elsevier Editora.

Noleto, C. S. (2009). Carcinoma de células escamosas de origem cutânea e de plano nasal em pequenos animais. 53f. Monografia (Pós-graduação lato sensu especialista em clínica médica de pequenos animais). Faculdade de Medicina Veterinária, Universidade Camilo Castelo Branco, Brasília.

Paranhos, C. A. (2014). Neoplasias cutâneas caninas: um estudo descritivo de 4 anos. In Medicina Veterinária: Vol. Master of. Universidade de Trás-os-Montes e Alto Douro.

Plumb, D. C. (2018). Plumb's veterinary drug handbook: Desk. John Wiley \& Sons.

Ramos, A. T., Norte, D. M., Elias, F., \& Fernandes, C. G. (2007). Carcinoma de células escamosas em bovinos, ovinos e eqüinos: estudo de 50 casos no sul do Rio Grande do Sul. Brazilian Journal of Veterinary Research and Animal Science, 44, 5-13.

Rosolem, M. C., Moroz, L. R., \& Rodigheri, S. M. (2012). Carcinoma de células escamosas em cães e gatos: Revisão de literatura. PUBVET, 6, Art. 1295-1300.

Histórico do artigo:

Recebido: 21 de setembro de 2021

Aprovado: 24 de outubro de 2021

Disponível online: 22 de fevereiro de 2022
Licenciamento: Este artigoé publicado na modalidade Acesso Aberto sob a licença Creative Commons Atribuição 4.0 (CC-BY 4.0), a qual permite uso irrestrito, distribuição, reprodução em qualquer meio, desde que o autor e a fonte sejam devidamente creditados. 